\title{
Produção de cebolinha, solteira e consorciada com rúcula, com e sem \\ cobertura do solo com cama-de-frango
}

\section{Yield of bunching onion in mono-cropping system and intercropped with roquette with and without soil covering with chicken manure}

\author{
Néstor Antonio Heredia Zárate ${ }^{1 *}$; Maria do Carmo Vieira²; João Dimas Graciano \\ Rosimeire Pereira Gassi ${ }^{4}$; Fábio Benedito Ono ${ }^{5}$; Ana Helaise Amadori ${ }^{5}$.
}

\section{Resumo}

\begin{abstract}
Os objetivos do trabalho foram avaliar a produtividade e a renda bruta da cebolinha 'Todo Ano' e da Rúcula 'Cultivada', sob cultivo solteiro e consorciado, com-C e sem-S cobertura do solo com cama-defrango-CF. A colheita da rúcula foi aos 81 dias após a semeadura e da cebolinha aos 81, 139 e 174 dias após o plantio. A altura das cebolinhas foi influenciada pelo tipo de cultivo na primeira colheita e pela cobertura do solo nas três colheitas. As menores e maiores massas frescas médias de cebolinha obtidas na primeira $\left(1,55\right.$ e 3,58 tha $\left.\mathrm{t}^{-1}\right)$ e na segunda rebrota $\left(1,31\right.$ e 3,07 $\left.\mathrm{tha}^{-1}\right)$ superaram em $355,88 \%$ e $285,29 \%$ e em $203,39 \%$ e $160,17 \%$, respectivamente, a menor $\left(0,34 \mathrm{tha}^{-1}\right)$ e a maior produção $\left(1,18 \mathrm{t} \mathrm{ha}^{-1}\right)$ da primeira colheita. A maior altura $(24,59 \mathrm{~cm})$ e a maior massa fresca $\left(11,40 \mathrm{tha}^{-1}\right)$ das plantas de rúcula foram do cultivo solteiro com CCF. Ao relacionar as Razões de Área Equivalente-RAEs $(1,29$ e 1,71) e as rendas brutas (R $\$ 34.695,95$ e 16.251,10) obtidas nos solos CCF e SCF, respectivamente, observou-se que a menor RAE induziu à maior renda bruta. Na cebolinha, as maiores produtividade e renda bruta foram com o cultivo solteiro em solo CCF e, para o mercado de Dourados, pode-se aproveitar a rebrota das plantas. Para rúcula, foi melhor o consórcio com a cebolinha em solo CCF.

Palavras-chave:Allium fistulosum, L. Eruca sativa Mill, associação de culturas, resíduo orgânico, retorno
\end{abstract}

\begin{abstract}
The objectives of this work were to evaluate yield and gross income of 'Todo Ano' bunching onion and 'Cultivada' roquette under mono-cropping and intercropping system, with (C) and without (S) soil covering with chicken manure (CF). Harvest of roquette was on 81 days after sowing and of bunching onion on 81, 139 and 174 days after planting. Height of bunching onion was influenced by type of cropping in the first harvest and by soil covering in both three harvests. The greatest and the smallest average fresh masses of bunching onion which were obtained in the first $\left(1.55\right.$ and $\left.3.58 \mathrm{tha}^{-1}\right)$ and in the second ( 1.31 and $\left.3.07 \mathrm{tha}^{-1}\right)$ re-sprouting were superior in $355.88 \%$ and $285.29 \%$ and in $203.39 \%$ and $160.17 \%$, respectively, than the smallest $\left(0.34 \mathrm{tha}^{-1}\right)$ and the greatest yield ( $\left.1.18 \mathrm{tha}-1\right)$ of the first harvest.
\end{abstract}

1 Professor Adjunto e Bolsista de Produtividade em Pesquisa do CNPq. Universidade Federal da Grande Dourados, Faculdade de Ciências Agrárias, Dourados - MS. E - mail: nahz@terra.com.br

2 Professor Titular e Bolsista de Produtividade em Pesquisa do CNPq. Universidade Federal da Grande Dourados, Faculdade de Ciências Agrárias, Dourados - MS. E - mail: mcvieira@ceud.ufms.br.

3 Professor da Universidade Federal da Grande Dourados, Faculdade de Ciências Agrárias, Dourados - MS.

4 Aluna do Curso de Mestrado em Agronomia da Universidade Federal da Grande Dourados. Dourados - MS.

5 Alunos do Curso de Agronomia da Universidade Federal da Grande Dourados. Dourados - MS.

* Autor para correspondência 
The highest height $(24.59 \mathrm{~cm})$ and the greatest fresh mass $\left(11.40 \mathrm{t} \mathrm{ha}^{-1}\right)$ of roquette plants were from mono-cropping system with CF soil covering. Relating Land Equivalent Ratios-LER (1.29 and 1.71) with gross income (R $\$ 34,695.95$ and 16,251.10) which were obtained from soils CCF and SCF, respectively, it was observed that the smaller LER induced the best gross income. For bunching onion, the highest yield and gross income were obtained with mono-cropping system in soil CCF and, for Dourados market, the resprouting of plants can be used. For roquette, intercrop system with bunching onion in soil CCF was the best.

Key words: Allium fistulosum, L., Eruca sativa Mill, intercropping, organic residue, income

\section{Introdução}

A consorciação de culturas é considerada sistema intermediário entre o monocultivo e as condições naturais de vegetação, onde diversas espécies coexistem em tempo e espaço, de forma equilibrada ecologicamente (SILVA, 1983). Uma das razões mais importantes para se cultivar duas ou mais culturas juntas é o aumento da produtividade por unidade de área e, em conseqüência, induzir o aumento da renda bruta do produtor rural. Para tanto, deve-se considerar o arranjo espacial, densidade das plantas, data de maturação das culturas e arquitetura da planta. Isso, visando proporcionar maximização da cooperação e minimização da competição entre as espécies (SULLIVAN, 2001). De modo geral, nos sistemas consorciados, os recursos água, luz, dióxido de carbono e nutrientes do solo são usados mais racionalmente e explorados ao máximo (SILVA, 1983). Muitos produtores associam a técnica do consórcio com redução dos riscos, pois se uma das culturas tem sua produção reduzida a outra pode compensar em produtividade parte dos prejuízos, permitindo ao produtor uma colheita razoável (INNIS, 1997).

As duas espécies de cebolinha comum - Allium schoenoprasun e A. fistulosum - são cultivadas por pequenos olericultores. A cultivar mais tradicional é Todo Ano, européia, que apresenta folhas de coloração verde-clara. Também têm sido introduzidas cultivares japonesas tipo "Nebuka" ou "Evergreen", de coloração verde-intensa (FILGUEIRA, 2000). A cebolinha é condimento muito apreciado pela população e cultivada em quase todos os lares brasileiros. A planta é considerada perene, apresenta folhas cilíndricas e fistulosas, com 0,30 a $0,50 \mathrm{~m}$ de altura, produz pequeno bulbo cônico, envolvido por uma película rósea, com perfilhamento e formação de touceira (FERREIRA; CASTELLANE; CRUZ, 1993; MAKISHIMA, 1993; FILGUEIRA, 2000; HEREDIA ZÁRATE; VIEIRA; BRATTI, 2003).

A cebolinha prefere solos sílico-argilosos, desde que sejam férteis, profundos e bem drenados, a arenoargilosos, com pH entre 6,0 e 6,5 e com bom teor de matéria orgânica. A adubação normalmente consiste na adição de esterco de galinha, na razão de 5 a 10 litros $\mathrm{m}^{-2}$. A colheita da cebolinha inicia-se entre $55 \mathrm{e}$ 60 dias após o plantio ou entre 85 e 100 dias após a semeadura, quando as folhas atingem de 0,20 a 0,40 $\mathrm{m}$ de altura (MAKISHIMA, 1993; FILGUEIRA, 2000). O rebrotamento é aproveitado para novos cortes, podendo um cultivo ser explorado por dois a três anos, principalmente quando são conduzidos em condições de clima ameno. Na comercialização para consumo ao natural, ela aparece só ou formando um conjunto com a salsa (Petroselinum crispum L.), o popular cheiro-verde (MAKISHIMA, 1993; FILGUEIRA, 2000). Nos últimos anos, a cebolinha tem sido cultivada para o abastecimento de agroindústrias de conserva (FERREIRA; CASTELLANE; CRUZ, 1993).

A popularidade da rúcula (Eruca sativa Mill.) como cultura é devido ao sabor picante de suas folhas, que são usadas em guarnição de saladas, petiscos e de grande variedade de pratos. A semente é utilizada como fonte de óleo na Índia e na tradicional fitoterapia, com vários propósitos (HARDER, 2004). A planta de rúcula é de clima ameno mas, quando cultivada em climas mais quentes desenvolve-se menos e apresenta folhas grosseiras. As folhas distribuem-se em torno do eixo principal formando roseta. A cultivar mais conhecida é 
a Cultivada. Tem sua época de plantio entre os meses de março e agosto. Recomenda-se espaçamento de 0,25 a $0,30 \mathrm{~m}$ entre sulcos e espaçamento de $0,05 \mathrm{~m}$ entre plantas e desbaste quando as plantas apresentarem $0,10 \mathrm{~m}$ de altura. A colheita normalmente se dá 30 a 40 dias após a semeadura cortando-se as folhas rente ao solo mas, o mercado de alguns Estados (PR, RJ, SP, MG, dentre outros) prefere plantas inteiras, após a eliminação das folhas senescentes (MAKISHIMA, 1993).

$\mathrm{Na}$ literatura consultada não foram encontrados relatos de trabalhos científicos relacionados com o consórcio de cebolinha e rúcula. Trabalho desenvolvido por Harder (2004) em Dourados-MS, para avaliar a produção e a renda bruta da rúcula 'Comercial'-R e do almeirão 'Amarelo'-A, cultivados solteiros sob três $\left(R_{3}\right.$ e $\left.A_{3}\right)$ e quatro linhas $\left(R_{4}\right.$ e $\left.A_{4}\right)$, e nos consórcios $\mathrm{R}_{4} \mathrm{~A}_{3}$ e $\mathrm{R}_{3} \mathrm{~A}_{4}$, mostrou que o arranjo $\mathrm{R}_{4} \mathrm{~A}_{3}$ poderia ter gerado incrementos monetários por hectare de $\mathrm{R} \$ 28.279,80$ e de $\mathrm{R} \$ 20.065,95$ na primeira colheita e $\mathrm{R} \$ 18.703,35$ e de $\mathrm{R} \$ 17.283,60$ na segunda colheita, em relação ao almeirão e a rúcula solteira.

Em Mato Grosso do Sul, há crescimento muito rápido da avicultura de corte e, portanto, têm aumentado as quantidades de resíduos utilizados nas camas-dos-frangos e a necessidade de eliminá-los. Pelas razões apresentadas, esses resíduos poderiam ser utilizados para melhorar as propriedades físicas e químicas do solo e, conseqüentemente, a produtividade de algumas culturas (RODRIGUES, 1995; VIEIRA, 1995; VIEIRA, HEREDIA ZÁRATE; SIQUEIRA, 1995; HEREDIA ZÁRATE; VIEIRA; SILVA, 1997). Isso porque, a matéria orgânica contribui de modo decisivo em muitas propriedades físico-químicas do solo, como capacidade de troca de cátions, formação de complexos e quelatos com numerosos íons e retenção de umidade. As fontes mais comuns de resíduo orgânico são representadas pelos resíduos de culturas, estercos, compostos e outros (CALEGARI, 1998). A escolha do resíduo vegetal a ser utilizado é função de sua disponibilidade, variando entre as regiões e com a cultura na qual se fará seu emprego (KIEHL, 1985).

Para cebola (Allium cepa L.), Filgueira (2000) cita que ao se utilizar adubos orgânicos ricos em $\mathrm{N}$, tal como a torta de mamona ou o esterco de galinha, a adubação química nitrogenada pode ser reduzida ou dispensada. Na alface (Lactuca sativa L.) 'Grand Rapids', Heredia Zárate, Vieira e Cabeças Júnior (1997) compararam os efeitos das doses de cama-de-aviário em cobertura sobre a produção e observaram que com o uso de $14,0 \mathrm{t} \mathrm{ha}^{-1}$ houve aumento da produtividade em $249,6 \%$ e $134,2 \%$, respectivamente, em relação à ausência e ao uso de 7,0 t ha ${ }^{-1}$. Oliveira, Ferreira e Soares (1986), trabalhando com alho (Allium sativum L.), observaram que o rendimento de bulbos teve influência positiva da cobertura morta e relacionaram essa resposta com o efeito sobre a umidade do solo, mantendo-a em nível mais elevado e reduzindo perdas por evaporação, sendo por esta razão mais eficiente e recomendada em condições de escassez de água para irrigação.

Para cebolinha, Heredia Zárate, Vieira e Bratti (2003) relatam o estudo da produção da cultivar Todo Ano, em função da cama-de-frango de corte semidecomposta, incorporada ou em cobertura do solo, nas doses 0,7 e $14 \mathrm{tha}^{-1}$, com colheitas aos 60 e 95 dias após o plantio. Observaram que houve aumentos significativos de $21,4 \%$ e $79,8 \%$ de massa fresca e de $18,2 \%$ e $54,8 \%$ de massa seca das plantas cultivadas em solos com $14 \mathrm{tha}^{-1}$ de cama-de-frango de corte semidecomposta em cobertura do solo, respectivamente, em relação às cultivadas com $7 \mathrm{t}$ $\mathrm{ha}^{-1}$ e $0 \mathrm{t} \mathrm{ha}^{-1}$. Ao relacionar a renda bruta total, foi melhor a colheita aos 95 dias após o plantio, principalmente quando a cebolinha foi cultivada em solo com $14 \mathrm{t} \mathrm{ha}^{-1}$ da cama incorporada $(\mathrm{R} \$ 44.418,25)$.

O objetivo deste trabalho foi estudar a produtividade e determinar a renda bruta da cebolinha 'Todo Ano' e da Rúcula 'Cultivada', sob cultivo 
solteiro e consorciado, com e sem cobertura do solo com cama-de-frango.

\section{Material e Métodos}

O trabalho foi desenvolvido em área do Horto de Plantas Medicinais, da Universidade Federal de Mato Grosso do Sul, em Dourados-MS, entre 11 de junho e 21 de novembro de 2005. O solo é do tipo Latossolo Vermelho distroférrico, de textura argilosa, com as seguintes características químicas: $5,0 \mathrm{de} \mathrm{pH}$ em $\mathrm{CaCl}_{2} ; 25,0 \mathrm{~g} \mathrm{dm}^{-3}$ de M.O.; 23,0 mg dm${ }^{-3}$ de P; 5,1; 41,3 e 16,0 $\mathrm{mmol}_{\mathrm{c}} \mathrm{dm}^{-3}$ de $\mathrm{K}, \mathrm{Ca}$ e $\mathrm{Mg}$, respectivamente. O município de Dourados situa-se em latitude de $22^{\circ} 13^{\prime} 16^{\prime \prime S}$, longitude de $54^{\circ} 17^{\prime} 01^{\prime \prime} \mathrm{W}$ e altitude de $430 \mathrm{~m}$. O clima da região, segundo a classificação de Köppen, é Mesotérmico Úmido; do tipo Cwa, com temperaturas e precipitações médias anuais variando de $20^{\circ}$ a $24^{\circ} \mathrm{C}$ e 1250 a $1500 \mathrm{~mm}$, respectivamente.

A cebolinha 'Todo Ano' e a rúcula 'Cultivada' foram alocadas no campo em experimento conjunto, sendo estudadas cada uma delas como fatorial 2 (cultivos solteiro e consorciado) x 2 (com e sem cobertura do solo com cama-de-frango), perfazendo, dessa forma, no total, seis tratamentos. O arranjo dos tratamentos foi no delineamento experimental de blocos casualizados, com cinco repetições. As parcelas tiveram área total de $3,0 \mathrm{~m}^{2}(1,5 \mathrm{~m}$ de largura x 2,0 m de comprimento) e área útil de 2,0 $\mathrm{m}^{2}$ (1,0 m de largura do canteiro x 2,0 m de comprimento). A cebolinha foi cultivada com cinco fileiras no canteiro, espaçadas de $0,20 \mathrm{~m}$ entre elas e a rúcula, com quatro, espaçadas de $0,25 \mathrm{~m}(0,10 \mathrm{~m}$ entre plantas de rúcula e cebolinha). No consórcio, com cinco fileiras de cebolinha e quatro de rúcula (9 linhas), o espaçamento entre elas foi de $0,10 \mathrm{~m}$.

O terreno foi preparado com aração, gradagem e levantamento de canteiros com rotoencanteirador. Não foi realizada nenhuma forma de adubação. A propagação da rúcula foi por semeadura direta, enquanto a da cebolinha foi por mudas, preparadas no dia anterior ao do plantio. As irrigações foram feitas por aspersão com o intuito de manter o solo com aproximadamente $70 \%$ da capacidade de campo e que induziu a turnos de rega a cada dois dias. Durante os ciclos de cultivo, 81 dias para a rúcula e 174 dias para a cebolinha, o controle das plantas infestantes foi feito com auxílio de enxadas nas entrelinhas e com arranquio manual dentro das linhas. Ao se observar algumas plantas com as folhas apresentando sintomas de ataque de insetos, foi aplicado extrato de Nim (Azadirachta indica A. Juss).

Antes de cada colheita, quando as folhas das plantas das duas espécies apresentavam perda do brilho, como indicativo do ponto de colheita (HARDER, 2004), foram medidas as alturas das plantas por parcela, desde o nível do solo até a inflexão das folhas, utilizando-se régua graduada em centímetros. A colheita da rúcula, realizada aos 81 dias após a semeadura, consistiu no corte das folhas acima das folhas centrais novas, em torno de dois centímetros de altura. Foram feitas três colheitas da cebolinha, cortando-se o pseudocaule na altura do coleto, sendo a primeira aos 81 dias após o plantioDAP, a segunda e a terceira, correspondentes às rebrotas, aos 139 DAP e aos 174 DAP, respectivamente. As partes aéreas das plantas foram pesadas, para determinação das massas frescas. Os dados foram submetidos à análise de variância e testados por $\mathrm{F}$, a $5 \%$ de probabilidade.

O consórcio foi avaliado utilizando-se a expressão da Razão de Área Equivalente (RAE) proposta por Caetano, Ferreira e Araújo (1999), a saber: RAE = $\mathrm{Cc} \cdot \mathrm{Cs}^{-1}+\mathrm{Rc} \cdot \mathrm{Rs}^{-1}$, onde, respectivamente, $\mathrm{Cc} \mathrm{e}$ $\mathrm{Rc}=$ produções de cebolinha e rúcula, respectivamente, em consorciação e Cs e Rs = produções de cebolinha e rúcula, respectivamente, em cultivo solteiro. A validação do consórcio foi realizada pela determinação da renda bruta obtida por hectare cultivado. Para isso, foram comprados cinco maços de cebolinha (variação de 64,1 a 84,4 g e média de $76,4 \mathrm{~g}$ ) e cinco de rúcula (variação de 214,6 a 258,4 g e média de 231,7 g), em dois locais de venda no varejo de Dourados, em janeiro de 2006, 
e determinada sua massa fresca. No varejo, os custos dos maços de cebolinha variaram de $\mathrm{R} \$ 0,40$ a $\mathrm{R} \$$ 0,50 e os de rúcula entre $\mathrm{R} \$ 0,49$ a $\mathrm{R} \$ 0,89$ mas, segundo os vendedores, os preços pagos aos produtores foi de $\mathrm{R} \$ 0,25$ por maço de cebolinha e de $\mathrm{R} \$ 0,45$ por maço de rúcula. Posteriormente, efetuaram-se as conversões por hectare para o número de maços e determinada a renda bruta total, por cultivo e total.

\section{Resultados e Discussão}

As alturas das plantas de cebolinha foram influenciadas significativamente pelo tipo de cultivo na primeira colheita e pela cobertura do solo nas três colheitas (Tabela 1). O aumento significativo de 2,38 $\mathrm{cm}$ das plantas de cebolinha consorciadas com a rúcula $(23,99 \mathrm{~cm})$, na primeira colheita, em relação àquelas sob cultivo solteiro $(20,61 \mathrm{~cm})$, pode ter sido causada pela excreção de hormônios estimuladores de crescimento; no entanto, esse estímulo foi citado apenas para algumas variedades de arroz intercultivadas (WHATLEY; WHATLEY, 1982). Esses resultados diferem daqueles encontrados por Heredia Zárate, Vieira e Bratti (2003) que, estudando o consórcio cebolinha com salsinha (Petroselinum crispum), não encontraram efeito significativo dos tratamentos na altura das plantas.

Tabela 1. Altura das plantas da cebolinha 'Todo Ano', cultivadas solteiras e em consórcio com rúcula, em solo com e sem cobertura com cama-de-frango, em três épocas de corte. UFMS, Dourados -MS, 2005.

\begin{tabular}{lccc}
\hline Tratamento & \multicolumn{3}{c}{ Altura das plantas (cm) na colheita } \\
\cline { 2 - 4 } & Primeira & Segunda & Terceira \\
\hline Cultivo & & & \\
\hline Solteiro & $20,61 \mathrm{~b}$ & $21,65 \mathrm{a}$ & $22,27 \mathrm{a}$ \\
Consórcio & $23,99 \mathrm{a}$ & $21,23 \mathrm{a}$ & $22,28 \mathrm{a}$ \\
\hline Cobertura do solo & & & \\
\hline Com & $26,70 \mathrm{~A}$ & $22,66 \mathrm{~A}$ & $23,72 \mathrm{~A}$ \\
Sem & $17,90 \mathrm{~B}$ & $20,22 \mathrm{~B}$ & $20,83 \mathrm{~B}$ \\
\hline \multicolumn{1}{r}{ C.V. (\%) } & 16,19 & 3,91 & 2,15 \\
\hline
\end{tabular}

Médias seguidas pelas mesmas letras, nas colunas, não diferem pelo teste $\mathrm{F}$, a $5 \%$ de probabilidade

As maiores alturas das plantas de cebolinha foram obtidas nas plantas cultivadas em solo coberto com a cama de frango, com aumentos de $8,80 \mathrm{~cm}$ (primeira colheita), 2,44 cm (segunda colheita) e 2,99 cm (terceira colheita) em relação às alturas das plantas cultivadas em solo sem cobertura $(17,90 \mathrm{~cm} ; 20,22$ cm e $20,83 \mathrm{~cm}$, respectivamente). Vieira (1995) cita que o uso de resíduos orgânicos deverá estimular, especialmente no início do ciclo da cultura, desenvolvimento adequado da parte aérea, em termos de altura e área foliar. As diferenças de altura das plantas entre as colheitas mostram que as relações fonte-dreno podem ser alteradas pelas condições de cultivo (HARDER, 2004).
As produções de massa fresca, nas três colheitas, apresentaram efeito significativo da interação forma de cultivo e uso de cama-de-frango na cobertura do solo (Tabela 2). As maiores produções foram obtidas no cultivo solteiro, com cobertura do solo. Esse resultado é coerente com a citação de Büll (1993), de que a maximização da produção depende, dentre outros fatores, da capacidade suporte do meio e do sistema de produção adotado.

As maiores produções de massa fresca de cebolinha (Tabela 2), obtidas nas segunda e terceira colheitas, em relação à primeira, estão relacionadas com a reação das plantas ao corte, tal como Harder (2004) observou em rúcula e almeirão. A produção das rebrotas é mais rápida porque as plantas não têm de gastar energia com a formação de raízes. 
Tabela 2. Produção de massa fresca de plantas de cebolinha 'Todo Ano', cultivadas solteiras e em consórcio com rúcula, em solo com e sem cobertura com cama-de-frango, em três épocas de corte. UFMS, Dourados - MS, 2005.

\begin{tabular}{|c|c|c|c|c|c|}
\hline \multicolumn{2}{|l|}{ Tratamento } & \multicolumn{4}{|c|}{ Massa fresca $\left(\mathrm{t} \mathrm{ha}^{-1}\right)$} \\
\hline Cultivo & Cama & Primeira & Segunda & Terceira & Total \\
\hline \multirow[t]{2}{*}{ Solteiro } & Com & $1,66 \mathrm{a}$ & $4,97 \mathrm{a}$ & $3,97 \mathrm{a}$ & 10,60 \\
\hline & Sem & $0,33 \mathrm{~b}$ & $1,80 \mathrm{~b}$ & $1,46 \mathrm{~b}$ & 3,59 \\
\hline \multirow[t]{2}{*}{ Consórcio } & Com & $0,69 \mathrm{~A}$ & $2,18 \mathrm{~A}$ & $2,16 \mathrm{~A}$ & 5,03 \\
\hline & Sem & $0,34 \mathrm{~A}$ & $1,30 \mathrm{~B}$ & $1,16 \mathrm{~B}$ & 2,80 \\
\hline \multicolumn{2}{|c|}{ C.V. $(\%)$} & 56,44 & 24,86 & 14,85 & \\
\hline
\end{tabular}

Médias seguidas pelas mesmas letras, nas colunas, não diferem pelo teste $\mathrm{F}$, a $5 \%$ de probabilidade.

Em relação à eficiência do aproveitamento das rebrotas, observou-se que as menores e maiores produções médias de massa fresca obtidas na primeira e na segunda rebrotas foram maiores em $355,88 \%$ e $285,29 \%$ e em $203,39 \%$ e $160,17 \%$, respectivamente, em relação à menor e à maior produção da primeira colheita (Tabela 2). Esses resultados mostram maior valorização quando se considera o período de 58 dias entre a primeira e a segunda colheitas e de 35 dias entre a segunda e a terceira colheitas. Clark et al (1990), citado por Kunelius e McRae (1998), relatam que para almeirão (Cichorium intybus L.), intervalos de corte das plantas de quatro semanas, com altura de corte de $10 \mathrm{~cm}$, resultaram em alta relação limbo/pecíolo e alta produtividade, não prejudicando a rebrota.
$\mathrm{Na}$ rúcula, observou-se efeito significativo da interação tipo de cultivo e cobertura do solo com cama-de-frango, na altura das plantas e na produção de massa fresca (Tabela 3). A maior altura das plantas e a maior produção de massa fresca foram do tratamento cultivo solteiro com cobertura do solo com cama-de-frango. Isso sugere que as plantas solteiras tiveram melhor adaptabilidade, normalmente sendo relacionada com a manutenção da eficiência na absorção ou no uso da água, dos nutrientes e do $\mathrm{CO}_{2}$ (Larcher, 2000). No caso da cama-de-frango utilizada em cobertura, ela deve ter contribuído na regulação da temperatura e na manutenção da umidade do solo (CALEGARI, 1998).

Tabela 3. Altura de plantas e produção de massa fresca da rúcula 'Cultivada', em cultivo solteiro e em consórcio com cebolinha, em solo com e sem cobertura com cama-de-frango. UFMS, Dourados - MS, 2005.

\section{Tratamento}

\begin{tabular}{lccc}
\hline \multicolumn{1}{c}{ Cultivo } & Cama & Altura $(\mathrm{cm})$ & Massa fresca $\left(\mathrm{t} \mathrm{ha}^{-1}\right)$ \\
\hline Solteiro & Com & $24,59 \mathrm{a}$ & $11,40 \mathrm{a}$ \\
& Sem & $14,57 \mathrm{~b}$ & $3,91 \mathrm{~b}$ \\
\multirow{2}{*}{ Consórcio } & Com & $21,09 \mathrm{~A}$ & $9,39 \mathrm{~A}$ \\
& Sem & $15,84 \mathrm{~B}$ & $3,65 \mathrm{~B}$ \\
\hline & C.V. (\%) & 11,25 & 24,43 \\
\hline
\end{tabular}

Médias seguidas pelas mesmas letras, nas colunas, não diferem pelo teste F, a 5\% de probabilidade 
Os aumentos produtivos das plantas de cebolinha (Tabela 2) e de rúcula (Tabela 3), cultivadas com uso da cama-de-frango na cobertura do solo, tanto solteiras como consorciadas, podem ter acontecido em razão de que a sua matéria orgânica ativa os processos microbianos fomentando, simultaneamente, a estrutura, a aeração e a capacidade de retenção de água (SILVA JÚNIOR; SIQUEIRA,1997). Atua ainda como regulador da temperatura do solo, retarda a fixação do $\mathrm{P}$ mineral e fornece produtos da decomposição orgânica que favorecem o desenvolvimento da planta (RODRIGUES, 1995; NOVAIS; SMYTH, 1999).

As razões de área equivalente (RAE) para os consórcios cebolinha e rúcula, em solo com e sem cobertura com cama-de-frango, respectivamente, foram superiores em $29 \%$ e $71 \%$ em relação aos seus respectivos cultivos solteiros, indicando que os consórcios foram efetivos (Tabela 4). Os valores obtidos para a RAE são coerentes com as citações de Sullivan (2001), Heredia Zárate, Vieira e Bratti (2003), Salvador (2003) e de Harder (2004), de que o aumento da produtividade por unidade de área é uma das razões mais importantes para se cultivar duas ou mais culturas no sistema de consorciação, porque permite melhor aproveitamento da terra e de outros recursos disponíveis, resultando em maior rendimento econômico.

Ao relacionar a renda bruta, observou-se que para o produtor de cebolinha, o cultivo solteiro em solo coberto com cama-de-frango poderia ter induzido aumentos monetários de $\mathrm{R} \$ 22.938,50$ e $\mathrm{R} \$ 18.434,65$, em relação ao cultivo solteiro e ao consorciado em solo sem cobertura e perda de $\mathrm{R} \$ 10,20$ em relação ao cultivo consorciado em solo com cobertura (Tabela 4). Para o produtor de rúcula, o consórcio com a cebolinha em solo coberto com cama-de-frango foi o melhor já que poderia ter induzido aumentos monetários de $\mathrm{R} \$ 12.555,50 ; \mathrm{R} \$ 27.102,20$ e $\mathrm{R} \$ 18.444,85$ em relação aos cultivos de rúcula solteiros, em solo com e sem cobertura, e ao consórcio em solo sem cobertura, respectivamente.

Tabela 4. Razão de área equivalente (RAE) e renda bruta do produtor considerando a produção total da massa fresca da cebolinha 'Todo Ano' e da rúcula 'Cultivada', em cultivo solteiro e consorciado, em solo com e sem cobertura com cama-de-frango. UFMS, Dourados - MS, 2005.

\begin{tabular}{|c|c|c|c|c|c|c|c|}
\hline \multirow[t]{2}{*}{ Cultivo } & \multirow[t]{2}{*}{ Espécie } & \multirow[t]{2}{*}{ Cama } & \multirow{2}{*}{$\begin{array}{l}\text { Massa } \\
\left(\mathrm{t} \mathrm{ha}^{-1}\right)\end{array}$} & \multirow{2}{*}{$\begin{array}{l}\text { Maços } \\
\left(\mathrm{n}^{\mathrm{o}} \mathrm{ha}^{-1}\right)\end{array}$} & \multirow[t]{2}{*}{ RAE } & \multicolumn{2}{|c|}{ Renda bruta $\left(\mathrm{R} \$ \mathrm{ha}^{-1}\right)^{2}$} \\
\hline & & & & & & Por cultivo & Total \\
\hline \multirow[t]{4}{*}{ Solteiro } & Cebolinha & Com & 10,60 & 138.743 & 1,00 & $34.685,75$ & $34.685,75$ \\
\hline & & Sem & 3,59 & 46.989 & 1,00 & $11.747,25$ & $11.747,25$ \\
\hline & Rúcula & Com & 11,40 & 49.201 & 1,00 & $22.140,45$ & $22.140,45$ \\
\hline & & Sem & 3,91 & 16.875 & 1,00 & $7.593,75$ & $7.593,75$ \\
\hline Consórcio & Cebolinha & Com & 5,03 & 65.837 & & $16.459,25$ & \\
\hline 1 & Rúcula & & 9,39 & 40.526 & 1,29 & $18.236,70$ & $34.695,95$ \\
\hline Consórcio & Cebolinha & Sem & 2,80 & 36.649 & & $9.162,25$ & \\
\hline 2 & Rúcula & & 3,65 & 15.753 & 1,71 & $7.088,85$ & $16.251,10$ \\
\hline
\end{tabular}

${ }^{1}$ Divisão da massa obtida no trabalho pelas médias de massa dos maços, sendo $76,4 \mathrm{~g}$ para cebolinha e 231,7 g para rúcula.

${ }^{2} \mathrm{R} \$ 0,25$ por maço de cebolinha e R $\$ 0,45$ por maço de rúcula, preço pago ao produtor. Fonte: Vendedores de hortaliças no varejo, em 27-1-2006. 
Ao relacionar as RAEs $(1,29$ e 1,71) e as rendas brutas (R $\$ 34.695,95$ e $\mathrm{R} \$ 16.251,10)$ obtidas nos solos com e sem cobertura com cama-de-frango, respectivamente, observou-se que a menor RAE induziu a maior renda bruta. Isso porque, o objetivo principal da produção agrícola é maximizar lucros, com minimização de custos, então, ao planejar a produção agrícola não se deve pensar apenas em otimizar a produção em determinada condição de cultivo, mas também na alocação adequada dos recursos disponíveis (HEREDIA ZÁRATE; VIEIRA, 2004). Heredia Zárate (2005) estudando a cebolinha e o coentro (Coriandrum sativum) observaram que para o produtor de coentro o consórcio cebolinha três linhas e coentro quatro linhas foi o pior, já que, apesar de a RAE ter sido superior a 1,00 , induziria perda por hectare de $\mathrm{R} \$ 99,42$.

\section{Conclusões}

Pelos resultados obtidos, conclui-se que as maiores produtividade e renda bruta da cebolinha foram com o cultivo solteiro em solo coberto com cama-de-frango e, para o mercado de Dourados-MS, pode-se aproveitar a rebrota das plantas. Para rúcula, foi melhor o consórcio com a cebolinha em solo coberto com cama-de-frango.

\section{Agradecimentos}

Ao CNPq, pelas bolsas concedidas e à FUNDECT-MS, pelo apoio financeiro

\section{Referências}

BÜLL, L. T. Cultura do milho: fatores que afetam a produtividade. Piracicaba: POTAFOS, 1993.

CAETANO, L. C. S.; FERREIRA, J. M.; ARAÚJO, M. Produtividade da alface e cenoura em sistema de consorciação. Horticultura Brasileira, Brasília, v.17, n.2, p.143-146, maio 1999.

CALEGARI, A. Espécies para cobertura do solo. In: In: DAROLT, MR (Coord.). Plantio direto: pequena propriedade sustentável. Londrina: IAPAR, 1998. p.65-94

FERREIRA, M. E.; CASTELLANE, P. D.; CRUZ, M. C. P. Nutrição e adubação de hortaliças. In: SIMPÓSIO SOBRE NUTRIÇÃO E ADUBAÇÃO DE HORTALIÇAS, 1990, Jaboticabal. Anais... Piracicaba: POTAFOS, 1993. p.473476.

FILGUEIRA, F.A.R. Novo manual de olericultura: agrotecnologia moderna na produção e comercialização de hortaliças. Viçosa: UFV, 2000.

HARDER, W.C. Produção e renda bruta de rúcula (Eruca sativa Mill.) 'Cultivada' e de almeirão (Cichorium intybus L.) 'Amarelo', em cultivo solteiro e consorciado. 2004. Dissertação (Mestrado em Agronomia) Universidade Federal de Mato Grosso do Sul, Dourados, 2004.

HEREDIA ZÁRATE, N. A Produção e renda bruta de cebolinha e de coentro em cultivo solteiro e consorciado. Semina: Ciências Agrárias, Londrina, v.26, n.2, p.141-146, abr.jun. 2005.

HEREDIA ZÁRATE, N.A.; VIEIRA, M.C. Produção e renda bruta da cebolinha solteira e consorciada com espinafre. Horticultura Brasileira, Brasília, v.22, n.4, p.811814, out./dez. 2004.

HEREDIA ZÁRATE, N.A.; VIEIRA, M.C.; BRATTI, R. Efeitos da cama-de-frangos e da época de colheita sobre a produção e a renda bruta da cebolinha 'Todo Ano'. Pesquisa Agropecuária Tropical, Goiânia, v.33, n.2, p.7378, jul./dez.,2003.

HEREDIA ZÁRATE, N.A.; VIEIRA, M.C.; CABEÇAS JÚNIOR, O. Produção de alface em função de doses e formas de aplicação de cama de aviário semi-decomposta. Horticultura Brasileira, Brasília, v.15, n.1, p.65-67, maio 1997.

HEREDIA ZÁRATE, N.A.; VIEIRA, M.C.; SILVA, R.M.M.F. Produção de cinco clones de inhame em cinco épocas de plantio, em Dourados - MS. SOBInforma, Rio de Janeiro, v.16, n.1, p.18-19, 1997.

INNIS, D.Q. Intercropping and the scientific basis of the traditional agriculture. London: Intermediate Publications, 1997. 179p.

KIEHL, E.J. Fertilizantes orgânicos. Piracicaba: Agronômica Ceres, 1985.

KUNELIUS, H.T.; McRAE, K.B. Forage chicory persists in combination with cool season grasses and legumes. Canadian Journal of Plant Science, Ottawa v.897, p.197200, 1998.

LARCHER, W. Ecofisiologia vegetal. São Carlos: RiMa Artes e Textos, 2000. 
MAKISHIMA, N. O cultivo de hortaliças. Brasília: EMBRAPA-CNPH: EMBRAPA-SPI, 1993. (Coleção Plantar, 4)

NOVAIS, R.F.; SMYTH, T.J. Fósforo em solo e planta em condições tropicais. Viçosa: UFV, DPS, 1999. 399p.

OLIVEIRA, A.P. ; FERREIRA, F.A.; SOARES, J.G. Uso da cobertura morta no cultivo do alho. Informe Agropecuário, Belo Horizonte, v.12, n.142, p.34-36, 1986.

RODRIGUES, E. T. Seleção de cultivares de alface (Lactuca sativa L.) para cultivo com composto orgânico. 1995. Tese (Doutorado) - Universidade Federal de Viçosa, Viçosa.

SALVADOR, D.J. Produção e renda bruta de cebolinha e de almeirão em cultivo solteiro e consorciado. Dourados, 2003. Monografia (Bacharelado em Ciências Biológicas) Universidade Federal do Mato Grosso do Sul.

SILVA JÚNIOR, J.P.; SIQUEIRA, J.O. Aplicação de formononetina sintética ao solo como estimulante da formação de micorriza no milho e na soja. Revista Brasileira de Fisiologia Vegetal, Brasília, v.9, n.1, p.35-41, 1997.
SILVA, N.F. Consórcio de hortaliças. In: VIEIRA, M.C.; HEREDIA; CASALI, V.W.D. Seminários de Olericultura. Viçosa:UFV, 1983. v.7, p.1-19.

SULLIVAN, P. Intercropping principles and production practices. 2001. Disponível em: <www.attra.org/attra-pu/ intercrop.html\#abstratNational > Acesso em: 3 set. 2003.

VIEIRA, M. C.; HEREDIA ZÁRATE, N. A.; SIQUEIRA, J. G. Produção de repolho louco, considerando uso de camade-aviário incorporada e em cobertura, em Dourados MS. SOBInforma, Curitiba, v.14, n.1/2, p.20-21, 1995.

VIEIRA, M.C. Avaliação do crescimento, da produção de clones e efeito de resíduo orgânico e de fósforo em mandioquinha-salsa no Estado de Mato Grosso do Sul. 1995. Tese (Doutorado) - Universidade Federal de Viçosa, Viçosa.

WHATLEY, J.M.; WHATLEY, F.R. A luz e a vida das plantas. São Paulo: Pedagógica e Universitária, 1982. 